\title{
SOBRE O CONCEITO DE COMPORTAMENTO: RÉPLICA
}

\author{
FILIPE LAZZERI ${ }^{1}$
}

UNIVERSIDADE DE SÃo PAULO, BRASIL

\begin{abstract}
1- Trabalho realizado a partir de pesquisa com apoio de bolsa concedida ao autor pela Fundação de Amparo à Pesquisa do Estado de São Paulo (FAPESP), \# 2012/00059-2. Endereço profissional: Departamento de Filosofia/Faculdade de Filosofia, Letras e Ciências Humanas, Universidade de São Paulo, Av. Prof. Luciano Gualberto, 315 (Cidade Universitária), CEP: 05508-900, São Paulo, SP, Brasil. E-mail: filipelazzeri@gmail.com
\end{abstract}

No que se segue, procurarei responder aos comentários de Tonneau (2013b), Todorov e Henriques (2013), Carrara e Zilio (2013b) e Botomé (2013b) feitos ao meu trabalho 'Um estudo sobre definições de comportamento' (Lazzeri 2013a). De modo geral, discordo das objeções desses autores ao meu referido artigo. Por isso, as presentes réplicas consistirão largamente em contraobjeções (em que identifico equívocos nas referidas críticas).

Como tenho grande respeito pelos autores, é-me um pouco penoso apontar o que considero ser sérios equívocos em suas críticas. Mas é preciso que esses equívocos sejam notados. Concerne-nos, aqui, em comum, o progresso em torno do conceito em pauta (o de comportamento), de modo que espero que considerem minhas réplicas apenas amistosamente, apesar do tom delas ser algo negativo.

\section{RESPOSTAA BOTOMÉ (2013B)}

O texto de Botomé (2013b) oferece algumas reflexões sobre o comportamento operante certamente interessantes. Porém, discordo da objeção de Botomé (2013b) às duas definições de comportamento que, em Lazzeri (2013a), propus.

Após reconhecer a utilidade de distinções que fiz em Lazzeri (2013a), Botomé (2013b) diz:

As definições propostas ao final do artigo de Lazzeri, porém, parecem mais amplas do que aquilo que é a esfera de abrangência da Análise do Comportamento ..., considerados os conceitos de 'comportamento operante' e de 'contingências de reforço'. As contribuições de Lazzeri referidas ... não parecem incluir ou referir-se às descobertas específicas no que diz respeito a esses dois referenciais [sic.].

A objeção de Botomé (2013b) é ambígua. (Ou seja, Botomé pode significar pelo menos duas coisas muito diferentes nessa objeção.) Quer ele dizer (i) que as definições que propus são demasiadamente amplas, por dizerem respeito a mais do que comportamentos (no sentido de respostas) operantes? Ou quer ele dizer (ii) que as definições que propus são demasiadamente restritivas, por supostamente não incluírem comportamentos (no sentido de respostas) operantes? (Eu dou por suposto que Botomé fale de comportamento, nesse trecho, no sentido de resposta ou ocorrência, e não de comportamento como padrão ou classe de respostas; pois eu deixei claro que o objeto de minhas definições e de meu estudo mais geral em Lazzeri 2013a é a noção de comportamento na acepção de resposta ou ocorrência.)

Em qualquer um desses casos, a objeção, a meu ver, é equivocada. (Botomé 2013b pode ter querido afirmar algo diferente de (i) e (ii) nessa objeção. Porém, meu ponto é que, se ele quis dizer (i) ou (ii), como parece ser o caso pois (i) e (ii) são as interpretações mais naturais da referida passagem -, então sua objeção é equivocada.) Analisemo-la inicialmente sob o ângulo da interpretação (i). Sob esse ângulo, ela pode ser reconstituída, em termos semiformais, do seguinte modo:

(1) Se as definições propostas por Lazzeri (2013a) incluem na extensão do definiendum mais do que respostas operantes, então essas definições são muito amplas. [Premissa]

(2) As definições propostas por Lazzeri (2013a) incluem na extensão do definiendum mais do que respostas operantes. [Premissa]

(3) Logo, as definições propostas por Lazzeri (2013a) são muito amplas. [De (1) e (2), modus ponens]

Sob essa interpretação, a objeção é malsucedida. Pois o definiendum de minhas definições em Lazzeri (2013a) não é resposta operante; mas, antes, comportamento (como resposta ou ocorrência) em um 
sentido mais geral - que engloba em sua extensão não só respostas operantes, mas também, por exemplo, ocorrências de padrões modais de ação, taxias, dentre outras. A extensão do definiendum claramente não se restringe a respostas operantes (cf. também Lazzeri 2014a). Ou seja, a premissa 1 da objeção, sob a interpretação (i), é falsa

Analisemos a objeção de Botomé (2013b), agora, sob o ângulo da interpretação (ii). (A ambiguidade da objeção de Botomé admite interpretações bastante opostas.) Sob esse ângulo, ela pode ser reconstituída do seguinte modo:

(1) Se as definições propostas por Lazzeri (2013a) não incluem na extensão do definiendum respostas operantes, então essas definições são muito restritivas. [Premissa]

(2) As definições propostas por Lazzeri (2013a) não incluem na extensão do definiendum respostas operantes. [Premissa]

(3) Logo, as definições propostas por Lazzeri (2013a) são muito restritivas. [De (1) e (2), modus ponens]

Também sob essa segunda interpretação, a objeção revela-se malsucedida. Pois eu mostrei em Lazzeri (2013a) que ambas as definições que sugiro (cf. também Lazzeri 2013b) abrangem as respostas operantes. Afinal, essas definições estabelecem (no caso da definição D.2, explicitamente, enquanto que, na D.1, implicitamente) como condições para que algo conte como extensão do definiendum que se trate de algo cuja etiologia envolva parcialmente processos de seleção pelas consequências (para utilizar a terminologia de Skinner 1981), em conjunção com objetos, eventos ou condições do ambiente presente atuando como estímulos sensoriais. Respostas operantes são coisas que um organismo realiza em função de condicionamento operante (que é um tipo se seleção pelas consequências), em combinação com estímulos sensoriais (exteroceptivos, proprioceptivos ou interoceptivos, em geral) com os quais o organismo interage no ambiente presente. Portanto, concordo, é claro, que respostas operantes são comportamentos (na acepção relevante), mas discordo que elas não sejam abrangidas em minhas definições de comportamento.

Botomé (2013b), em sua objeção, não oferece sequer um contraexemplo a (D.1) ou (D.2). A premissa 2 de sua objeção, sob a interpretação (ii), é apenas afirmada. O ônus da prova, portanto, fica com Botomé (2013b), caso ele tenha querido dizer (ii).

Por conseguinte, a objeção é falha, seja sob a interpretação (i) ou (ii). Gostaria de salientar, ainda, um ponto menor sobre o texto de Botomé (2013b) - menor porque não chega a afetar seu argumento -, mas que não deve passar despercebido pelo(a) leitor(a). Botomé (2013b) associa os critérios que sugiro em Lazzeri (2013a) para uma definição de comportamento (na acepção e para os propósitos que delimitei) àqueles gerais de Copi (1982). Isso é equivocado, porque, em primeiro lugar, eu não utilizo todos os critérios de Copi (1982). Em segundo lugar, dentre os critérios que sugiro, há um (nomeadamente, aquele relacionado à captura das nuanças mínimas do definiendum) que não é estabelecido por Copi (1982). E, por último, os critérios gerais de Copi (1982) são para definições por gênero e diferença específica (isto é, para definições em termos de condições necessárias e conjuntamente suficientes), enquanto que eu delimitei outros tipos de definição que podem ser cabíveis para o definiendum em questão (ver Lazzeri 2013a; também Lazzeri 2014b).

\section{RESPOSTA A TODOROV E HENRIQUES (2013)}

A meu ver, Todorov e Henriques (2013) apresentam algumas observações bastante interessantes aos outros textos do número especial da REBAC. Concordo com Todorov e Henriques (2013), por exemplo, com sua observação, semelhante a uma que faço em Lazzeri (2013b), de que Botomé (2013a) e Carrara e Zilio (2013a) não levam (pelo menos suficientemente) em conta (naqueles textos específicos, é claro) comportamentos de tipos outros que os operantes.

Todorov e Henriques (2013) reconhecem que minhas análises em Lazzeri (2013a) são consistentes, em geral, com a análise do comportamento skinneriana, e que podem ser úteis. Porém, eles lançam a objeção (embora não de uma maneira tão evidente ao leitor) de que eu estaria, em Lazzeri (2013a), igualando a noção de comportamento com a de contingência, o que seria equivocado. Todorov e Henriques (2013) alegam que Lazzeri (2013a) "alinha comportamento a contingências". Alegam inclusive que "[P]ara todos os autores" do número especial da REBAC o conceito de comportamento é "um conceito diferente do de resposta".

No entanto, essa objeção não critica algo que eu disse ou que se seguisse do que eu disse (em Lazzeri 2013a); antes, ela envolve uma representação equivocada do que eu disse. A objeção pode ser reconstituída, em termos semiformais, do seguinte modo:

(1) Se as definições de Lazzeri (2013a) fazem equivaler o definiendum à noção de contingência, então, se o definiendum não equivale à noção de contingência, então as definições de Lazzeri (2013a) são implausíveis. [Premissa] (2) As definições de Lazzeri (2013a) fazem equivaler o definiendum à noção de contingência. [Premissa]

(3) Logo, se o definiendum não equivale à noção de contingência, então as definições de Lazzeri (2013a) são implausíveis. [De (1) e (2), modus ponens]

(4) $\mathrm{O}$ definiendum não equivale à noção de contingência. [Premissa]

(5) Logo, as definições de Lazzeri (2013a) são implausíveis. [De (3) e (4), modus ponens]

Tal objeção é equivocada na medida em que a premissa 2 dela é falsa. Ou seja, é falso que eu tenha proposto, ou que se siga do que eu propus, que 
comportamentos sejam contingências (no sentido técnico do termo). Em primeiro lugar, eu deixei claro em Lazzeri (2013a) que o definiendum das duas definições que proponho naquele trabalho (isto é, de D.1 e D.2), bem como das definições que examino criticamente naquele trabalho, é comportamento na acepção de resposta ou ocorrência. Ora, por certo, concordo que comportamento, em tal acepção, não é o mesmo que contingência. Pois contingência é uma relação funcional (isto é, diz respeito a correlações entre os elementos - variáveis dependentes e independentes identificados por uma análise funcional); por exemplo, no caso de uma contingência de reforço, a contingência é uma correlação entre respostas, consequências (reforçadoras ou punitivas) e estímulos discriminativos. Já os comportamentos, no sentido de respostas, são apenas parte do que está envolvido em contingências, portanto não podendo ser identificados com contingências. Comportamentos (na acepção de respostas) são coisas que um organismo realiza, em momentos e locais específicos. Contingências não são o tipo de coisa que um organismo realize. Minhas definições de comportamento, na acepção relevante, de modo nenhum fazem equivaler comportamento com contingência, porque eu digo nelas que comportamento é algo que um organismo faz (ou seja, é uma mudança realizada por um organismo) cuja etiologia envolva histórias de seleção por consequências, em conjunção com aspectos do ambiente atuando como estímulos sensoriais. As contingências, segundo minha proposta, estão envolvidas na etiologia dos comportamentos (na acepção de respostas), mas não são elas mesmos comportamentos (pelo menos na acepção de respostas). ${ }^{1}$

\section{RESPOSTA A CARRARA E ZILIO (2013B)}

Considero que Carrara e Zilio (2013b) apresentam algumas contribuições interessantes para o tema da noção de comportamento. No entanto, discordo das objeções de Carrara e Zilio (2013b) a Lazzeri (2013a). Vejamo-las uma de cada vez.

Carrara e Zilio (2013b) inferem que eu estaria, ao falar em funções, comprometido com causas no futuro (invertidas) ou outros processos de existência bastante questionável. A objeção em que eles cometem esse equívoco é aquela à minha caracterização (na primeira seção de Lazzeri 2013a) e a uma de minhas duas definições (na parte final de Lazzeri 2013a) de comportamento (na acepção de respostas ou ocorrências) como sendo fenômenos que possuem funções. Segundo Carrara e Zilio (2013b):

1 Todorov e Henriques (2013) podem ter sido levados a fazer essa acusação equivocada por uma das definições que proponho basear-se em parte na de Moore (2008) (cf. Lazzeri 2013a). Pois Moore (2008) às vezes diz que comportamento é interação (o que é problemático). Porém, o fato é que nenhuma das definições que proponho incorre na falha de igualar resposta com interação.
Ao incluir na discussão sobre o conceito de comportamento um norte teleológico, resulta afetado [sic] o contexto da sua definição .... [S]e se depreende das asserções do autor que teleológico faça referência a comportar-se 'para', via conotação intencional, por certo essa é uma caracterização que escapa às formulações explicativas de comportamento no âmbito da AC [Análise do Comportamento]. Ao inverso, esta não postula referência ao futuro como causa determinante do comportamento, mas a alguma experiência de interação organismo-ambiente ....

$\mathrm{Ou}$ seja, Carrara e Zilio (2013b) alegam que, quando eu falo de caráter teleológico, propositivo ou dirigido a objetivos dos comportamentos (na acepção aqui relevante), estou assumindo que os comportamentos são causados por eventos ou condições futuras do ambiente; ou, em geral, por variáveis que não estão no conjunto de (para utilizar a expressão de Laudan et al. 1986) suposições guia (em particular, ontológicas) da análise do comportamento. Em termos semiformais, essa sua objeção é, de maneira aproximada, a seguinte:

(1) A caracterização dos comportamentos (na acepção relevante) feita por Lazzeri (2013a) afirma que eles têm funções. [Premissa]

(2) Se a caracterização dos comportamentos (na acepção relevante) feita por Lazzeri (2013a) afirma que eles têm funções, então Lazzeri (2013a) compromete-se com a ideia de que eles são causados por eventos ou condições futuras ou, de modo mais geral, incompatíveis com a análise do comportamento (como ciência). [Premissa]

(3) Logo, Lazzeri (2013a) compromete-se com a ideia de que comportamentos são causados por eventos ou condições futuras ou, de modo mais geral, incompatíveis com a análise do comportamento. [De (1) e (2), modus ponens]

Em nenhum momento em Lazzeri (2013a) comprometi-me com supostos eventos ou condições do ambiente futuro atuando como causas invertidas. Tampouco comprometi-me com quaisquer outras entidades ou princípios causais incompatíveis com a análise do comportamento (e.g., com propósitos entendidos de modo mentalista, isto é, como causas do comportamento de um nível não comportamental interior ao corpo).

Quando falo, em Lazzeri (2013a), do caráter teleológico do comportamento, expliquei que me refiro a características tais como a de comportamento (na acepção relevante) contrastar com coisas que correspondem à produção de um resultado meramente incidental por um organismo (e.g., chamar atenção de um predador incidentalmente) e com coisas que lhe acontecem por simples força de eventos ou objetos do ambiente externo imediato (e.g., cair incidentalmente) (cf. também Lazzeri 2014a; 2014b). Além disso, em uma de minhas definições de comportamento (a saber, D.1), segundo a qual ele (na acepção relevante) é algo que um organismo faz que possui 
uma ou mais funções e é parcialmente causado por aspectos do ambiente presente atuando como estímulos sensoriais, expliquei que funções devem ser entendidas conforme a teoria histórico-etiológica das funções, desenvolvida por autores tais como Wright (1976) e Millikan (1984). Funções, então, são entendidas em minha proposta, resumidamente falando, em termos de processos de seleção pelas consequências (no sentido de Skinner 1981), sejam estes filogenéticos (seleção natural) e/ou ontogenéticos (em especial, condicionamento operante) (para alguns pormenores, cf., e.g., Lazzeri 2013a; Millikan 1984; 1989). Comportamentos (incluindo respostas operantes, respostas reflexas, ocorrências de padrões modais de ação e afins) têm funções de modo similar a (e aqueles estabelecidos filogeneticamente de modo inclusive exatamente similar a) como, por exemplo, os olhos e dentes têm funções. Traços filogenéticos funcionais, em particular, têm funções na medida em que são adaptações; ou seja, grosso modo, na medida em que fazem o que fazem (no caso dos traços mencionados aqui como exemplos, propiciam que haja visão e trituram alimentos, respectivamente) pelo fato de que realizar isso foi selecionado na história evolutiva (cf., e.g., Sober 1984). Trata-se de uma perspectiva naturalista das funções, que não apenas é compatível com as ciências biológicas e inclusive a análise do comportamento, mas também, penso, úteis para essas áreas. Um organismo cair incidentalmente, por oposição a cair de propósito (e.g., quando um ator em uma peça de teatro quer representar uma queda), por exemplo, significa, simplificadamente falando, que: no primeiro caso, mas não no segundo, o acontecimento é tal que sua etiologia não envolve uma história seleção por consequências em conjunção com aspectos do ambiente presente atuando como estímulos sensoriais. $^{2}$ Assim, eu espero que esteja claro que a premissa 2 da objeção em questão de Carrara e Zilio (2013b) é falsa e, portanto, que essa objeção é equivocada.

Carrara e Zilio (2013b) afirmam, ainda, que:

[N]o caso de 'coisas que o organismo faz incidentalmente', que ... tropeçar em um galho ('sem querer') isso [sic] gera necessariamente uma mudança no ambiente. Se um leão produz, incidentalmente, ao tropeçar, algum ruído que afugente a caça, essa circunstância pode vir a controlar seu futuro comportamento de caçar, embora originalmente não tenha sido produzido com qualquer finalidade 'planejada'. O que determina, portanto, que muitos comportamentos aparentemente casuais se tornem funcionais é o pareamento de respostas e consequências, sob circunstâncias específicas.

Em nenhum momento neguei o que Carrara e Zilio (2013b) dizem nesse trecho, apesar de eles acharem que eu o faça. Isso a não ser que Carrara e Zilio (2013b) queiram dizer, nessa passagem, que o tropeçar do leão, ou que seu afugentar a caça ao tropeçar, seja um comportamento do

2 . Como apontei em Lazzeri (2013a), Moore (2008), que é um grande defensor das ideias de Skinner, fala algo parecido com isso. leão - e que, portanto, acontecimentos como deslizar incidentalmente (por oposição a quando, e.g., alguém desliza no gelo esquiando), cair ao ser fortemente empurrado por alguém, etc., se vierem a afetar a probabilidade de respostas futuras do organismo, contam como comportamentos. Se for isso o que Carrara e Zilio (2013b) querem dizer nesse trecho, então trata-se de uma afirmação muito problemática, suscetível a algumas das dificuldades que apontei em Lazzeri (2013a; cf. também Lazzeri 2014a; 2014b). Já se, por outro lado, não for isso o que eles estão dizendo no referido trecho, minhas análises em Lazzeri (2013a) são compatíveis com o que afirmam nele. Mais do que isso, nesse caso, o referido trecho está em conformidade com as definições que proponho de comportamento (na acepção relevante).

Uma outra objeção de Carrara e Zilio (2013b) é de que, em minha análise do conceito de comportamento, valho-me de noções como as de ação, reação e ocorrência, que, segundo eles, requerem explicação. Em particular:

'Ação' e 'reação', nessa perspectiva, não parecem constituirse [sic] como termos subsidiários à caracterização de qualquer das noções de comportamento, mais requerendo seu prévio esclarecimento conceitual, embora legítima a estratégia do autor para aclarar o campo de investigação escolhido.

Entretanto, na verdade, dei uma definição parcial das noções de ação e de reação na seção inicial de Lazzeri (2013a). Fiz uma definição de tipo extensional (quanto à forma da definição) e de precisão (quanto ao propósito da definição) dessas noções. ${ }^{3}$ Isto é, listei casos típicos de itens que são ações e de itens que são reações, no sentido mais ou menos convencionalizado de 'ação' e 'reação' do qual me vali naquele trabalho. Por ações, mencionei que entendo, nele, coisas tais como erguer o braço para fazer uma pergunta ou um gato puxar uma alavanca para sair de uma caixa; isto é, respostas operantes. Por reações, mencionei que entendo coisas tais como, por exemplo, um coelho piscar o olho frente a uma rajada de vento como estímulo eliciador, além de outros reflexos, quer incondicionados ou condicionados; bem como ocorrências de outros padrões que, como os reflexos incondicionados, são em grande medida estabelecidos filogeneticamente.

Gostaria de salientar a esse respeito mais duas observações. Apesar de Carrara e Zilio (2013b) admitirem que, em todo caso, minha análise do conceito de comportamento adota uma estratégia legítima, eles afirmaram que as noções das quais me valho nessa análise requerem, elas próprias, um esclarecimento. Porém, em primeiro lugar, é preciso levar em conta que uma análise conceitual, na linha da filosofia da linguagem ordinária, desempenha um papel de clarificar a geografia lógica de um conceito (isto é, suas nuanças mínimas, ou, ainda, as regras que regem seus usos típicos). Isso não requer que

3 . Sobre esses tipos de definição, cf., e.g., Cook (2009), Copi (1982), Lazzeri (2013a; 2014b). 
todos os conceitos envolvidos recebam uma definição explícita (cf., e.g., Austin 1957; Bennett \& Hacker 2003; Harzem \& Miles 1978).

Em segundo lugar, meu exercício de clarificação do conceito de comportamento teve um papel propedêutico; a saber, para o apoio argumentativo e formulação de minhas duas definições teóricas (em uma acepção de 'teórico' que indiquei em Lazzeri 2013a; cf. também Lazzeri 2014b), além de para meu exame de definições teóricas de comportamento (como resposta) encontradas na literatura científica e filosófica. No âmbito de uma definição teórica, convém, é claro, que noções tão ou mais obscuras do que a do definiendum sejam, se possível, explicadas. O conceito de função, por exemplo, no caso de minha definição (D.1), é o tipo de conceito que requer explicação. É por isso que, em Lazzeri (2013a), ao introduzir (D.1), falo de funções em um sentido mais específico do que na seção inicial daquele trabalho (a qual requeria neutralidade). Ou seja, ao introduzir (D.1), eu já havia explicado a definição de função que adoto.

Por fim, Carrara e Zilio (2013b) parecem questionar minha sugestão de que comportamentos de grupo são fenômenos por direito próprio. Para eles, falar em comportamento de grupo é apenas uma maneira metafórica de falar. Nas palavras de Carrara e Zilio (2013b), trata-se apenas de "uma figura de linguagem". Eles negam expressamente que haja comportamentos de grupo. (A posição deles a respeito já está explícita em Carrara e Zilio 2013a, como apontei em Lazzeri 2013b). Além disso, alegam que introduzir a noção de comportamento de grupo complica desnecessariamente a discussão.

Em Lazzeri (2013a), eu não entrei em pormenores a respeito do status ontológico dos comportamentos de grupo. Chamei atenção, na seção inicial daquele trabalho, para, dentre outras coisas, o fato de que uma análise conceitual revela que há um uso do conceito de comportamento que se refere a grupos (e.g., quando se fala de um grupo de leões caçando; de um grupo de pessoas fazendo um protesto; de um grupo de abelhas protegendo uma colmeia). Apontei que há propriedades que são exibidas por fenômenos que chamamos 'comportamentos de grupo' e que não o são por muitos dos comportamentos de organismos individuais; em especial, a propriedade de envolver cooperação. Para meus propósitos em Lazzeri (2013a), essas distinções eram suficientes, pois as definições que examinei, com uma exceção (a saber, a de Levitis et al. 2009), não têm como preocupação definir comportamentos inclusive de grupos, mas apenas de organismos individuais. As minhas propostas de definição de comportamento (na acepção relevante) em Lazzeri (2013a) inserem-se no âmbito dessa literatura que examinei.

Já em Lazzeri (2013b), eu argumentei de modo explícito que faz sentido falar-se de comportamentos de grupo por direito próprio, e não meramente como uma maneira metafórica de falar - embora eles sejam, como eu ressaltei (tanto em Lazzeri 2013a como em Lazzeri 2013b), formados por comportamentos de organismos individuais. Se eu estiver certo em Lazzeri (2013b) no que tange a isso, comportamentos de grupo existem, a não ser que se queira dizer que coisas como, por exemplo, espécies e países - que não são comportamentos de grupo, é claro, mas têm em comum com eles um caráter abstrato -, não existem. Digo caráter abstrato, aqui, no sentido de que coisas como comportamentos de grupos, espécies e países (diferentemente de, e.g., mesas, montanhas, árvores, organismos) não são coisas que podem ser tocadas, cheiradas, molhadas, etc. Os comportamentos dos organismos individuais, aliás, seja na acepção de resposta, seja na acepção de classe ou padrão de respostas, também possuem um caráter abstrato (cf. Lazzeri 2015a; 2015b).

Sobre o questionamento de que a noção de comportamento de grupo complicaria desnecessariamente a discussão, eu diria que concordo que essa noção, de certa forma, complica a discussão; mas discordo que o faça desnecessariamente. A meu ver, ela enriquece o debate sobre o conceito de comportamento em geral. Independentemente de como modelemos os comportamentos de grupo, o fato é que essa noção é importante. Por exemplo, acredito que ela é importante para os fundamentos da ciência ampla do comportamento sugerida por Skinner (1990), ${ }^{4}$ inclusive para adquirirmos maior clareza sobre a relação entre essa ciência com algumas outras ciências (sobretudo as sociais). Nessa medida, considero que o tópico dos comportamentos de grupo (o qual tem sido tratado amplamente em filosofia da ação; cf., e.g., Gilbert 2010; Pettit \& Schweikard 2006) merece atenção da análise do comportamento.

\section{RESPOSTA A TONNEAU (2013B)}

Tonneau (2013b) faz algumas observações interessantes sobre certos aspectos de Lazzeri (2013a). Porém, eu tenho ponderações a elas.

Em primeiro lugar, Tonneau (2013b) parece acatar os critérios que sugiro para uma definição de comportamento (na acepção relevante e em qualquer uma das formas de definição que delimitei em Lazzeri 2013a). Porém, ele sugere o acréscimo de mais um critério: “Aos critérios que Lazzeri detalha para uma definição adequada do comportamento, somaria outro: uma definição adequada teria que permitir uma distinção entre comportamento do organismo e comportamento das suas partes". Note-se que essa asserção é ambígua. Quer Tonneau (2013b), nessa passagem, sugerir (i) o acréscimo de um critério à minha lista de critérios (a) - (e) - ou seja, ao lado de critérios como o de que a definição não deve ser demasiado ampla, não deve ser demasiado restritiva, etc.? Ou quer ele sugerir,

4

Refiro-me à ciência tripartite do comportamento - englobando etologia, análise do comportamento e uma parte da antropologia -, ou mesmo quadripartite - se a fisiologia estiver sendo considerada como mais um dos integrantes -, sugerida por Skinner (1990). 
nessa passagem, (ii) mais um critério ao conjunto daqueles correspondentes a nuanças mínimas que elucido ao longo do artigo (embora predominantemente na seção inicial) associadas ao definiendum - tais como as de que se trata de algo que contrasta com estados, de algo que possui funções, de algo que contrasta com pelo menos várias atividades desenvolvimentais, etc.?

Seja sob a interpretação (i) ou (ii), penso que a sugestão de Tonneau (2013b) já está implicitamente abarcada por minhas distinções. No caso da interpretação (ii), ela já o está porque o definiendum, conforme delimitei, é o comportamento no sentido de respostas, em geral, de organismos (mudanças que os organismos realizam em momentos e lugares particulares). A princípio, não é um subconjunto da extensão do definiendum itens que correspondam ao que pudéssemos chamar de respostas de partes do corpo tomadas isoladamente. Deve-se notar, porém, evidentemente, que muitas coisas que um organismo realiza envolvem fundamentalmente atividades de partes dele (e.g., quando um organismo saliva; quando pisca os olhos; quando contrai os vasos sanguíneos).

No caso da interpretação (i), a sugestão de Tonneau (2013b) já está implicitamente abarcada também, porque o critério (e) que estabeleço em Lazzeri (2013a) prescreve que as nuanças mínimas do definiendum em pauta sejam capturadas pela definição, resguardando-se a possibilidade de revisão conceitual nelas. Se o definiendum tem - e ele parece efetivamente ter - como nuança mínima a característica de ser um fenômeno predicável, em geral, ao organismo como um todo, e não a partes isoladas do organismo, então a sugestão está abarcada.

Em segundo lugar, Tonneau (2013b) aponta, muito rapidamente, algo sobre a noção de fazer. Ele parece, aqui, (1) aludir ao que falou a respeito em Tonneau (2013a), dizendo que fazer é uma noção "inútil nesse contexto"; além de (2) dizer que fazer "implica em muito mais que cumprir com algum verbo ativo". Concordo com (2), mas, como Tonneau provavelmente admitiria (levando em conta o que ele fala em Tonneau 2013a), (2) não atinge, de maneira nenhuma, o argumento que articulei (em Lazzeri 2013a; cf. também Lazzeri 2013b) com base em Millikan (1993) contra a identificação entre organismo comportar-se e organismo fazer algo.

Quanto a (1), ao contrário do que Tonneau (2013b) alega, fazer não é uma noção "inútil nesse contexto". Pois fazer é uma noção similar à de uma mudança do organismo ou efetuada pelo organismo (Lazzeri 2013b), a qual não só é bastante útil, como logicamente legítima (não acarretando nenhuma incoerência ou circularidade viciosa).

Em terceiro lugar, Tonneau (2013b) faz uma observação (que não chega a ser uma crítica) sobre a distinção entre o interior e o exterior do corpo. Segundo ele:

"[O] salivar do cão não ocorre dentro do seu corpo, porque ... uma vez produzida, a saliva está na boca, mas não está no corpo! As atividades endócrinas que são componentes do salivar, contudo, ocorrem dentro do corpo do cão".

Essa passagem parece-me um contrassenso, pois o salivar é, justamente, até onde sei, o organismo realizar certas secreções endócrinas. O fato de que, dessa atividade, resulta saliva na boca, não torna o salivar algo que não ocorre no interior do corpo.

Tonneau (2013b) ainda diz, nesse tocante, que: Menciono este ponto porque a distinção que Lazzeri esboça entre o que o organismo faz 'no interior do corpo' (como salivar') e o que 'faz exteriormente' (como tocar violão) poderia ser mal interpretada. Uma interpretação correta do conceito de fronteira deixa claro que a superfície da boca (e, mais genericamente, do tubo digestivo), apesar de ser difícil de observar por fora, faz parte integral da fronteira do organismo e não do seu interior.

A distinção que utilizei em Lazzeri (2013a) entre interior e exterior do corpo é a distinção intuitiva. Se houver uma distinção mais útil e coerente entre interior e exterior do corpo, então poderá ser um incremento bem-vindo para nosso entendimento do definiendum. Quiçá aquela apresentada por Tonneau (2013a) se qualifique como tal (eu deixo isso em aberto aqui), mas eu tenho dúvida a respeito. Pois parece-me outro contrassenso dizer que, se algo ocorre, por exemplo, na superfície interna da boca ou, de modo mais geral, na superfície do tubo digestivo, ocorre fora do corpo.

A meu ver, no que tange a isso, seja como for, o importante é ter-se em conta que nem todo comportamento envolve locomoção ou movimentos do corpo observáveis por simples contemplação do que está fora da epiderme, do exoesqueleto ou análogo. Resumidamente falando, aos comportamentos com tal característica, chamo, seguindo de modo aproximado Skinner (e.g., 1976/1974), de encobertos. Note-se que a distinção entre comportamentos manifestos e encobertos, assim entendida, é uma distinção epistêmica (cf. Lazzeri 2013c; 2015b).

Por fim, Tonneau (2013b) questiona uma das condições que compõem o definiens tanto da minha definição (D.1) como da (D.2), a saber: a condição de que a mudança do organismo que conta como comportamento é tal que sua etiologia envolve objetos, eventos ou condições do ambiente presente atuando como estímulos sensoriais. Para Tonneau (2013b), essa condição não é plausível por duas razões: supostamente (I) definir estímulo sensorial envolveria introduzir a noção de comportamento, na acepção relevante, o que tornaria (D.1) e (D.2) circulares (em suas palavras, "O comportamento vem primeiro e sua definição não pode depender do conceito de estímulo"); e (II) há organismos que se comportam, mas não possuem sistema nervoso, mas falar de estímulos sensoriais pressupõe que se trate de coisas que dependem de sistema nervoso.

Considero que essa objeção de Tonneau (2013b) chama atenção para um ponto interessante, que é o de que, 
como Gibson (1960) apontara, a noção de estímulo, ou estímulo sensorial em particular, não é tão simples como pode parecer.5 Entretanto, a objeção mostra-se problemática. Em primeiro lugar, porque a afirmação (I) é bastante questionável. Tonneau (2013b) diz ter uma intuição de que (I) é o caso, mas sugiro que há razões em contrário, como se segue.

A fim de caracterizar, pelo menos parcialmente, o que entendo por estímulo sensorial, eu gostaria de começar explicitando o que entendo, de modo aproximado, por ambiente. A saber, entendo este, de modo aproximado, como o espaço que circunda todos os organismos e que os penetra, incluindo todos os objetos, eventos ou condições do universo, alguns dos quais são estímulos sensoriais potenciais. Objetos, eventos ou condições atuando (efetivamente) como estímulos sensoriais (seja exteroceptivos, proprioceptivos ou interoceptivos) não são o mesmo que ambiente. Eles são apenas estímulos sensoriais efetivos, que formam uma parte pequena do ambiente (uma distinção similar é feita por Gibson 1960). Já, por estímulos sensoriais efetivos, entendo, aproximadamente, os objetos, eventos ou condições do ambiente, seja interno ou externo à derme, ao exoesqueleto ou similar do organismo (e.g., objetos que tateamos ou vemos, uma inflamação causada pela picada de um mosquito), provocando a ativação de determinados receptores do organismo.

Nessa caracterização, ainda que a título de esboço, de estímulo sensorial, não há a presença da noção de comportamento (na acepção relevante aqui). Em Lazzeri (2013a), trabalhei com a hipótese de que fazer uso da noção de estímulo sensorial no definiens, em (D.1) e (D.2), não envolve nenhuma circularidade, ou pelo menos nenhuma circularidade viciosa. Eu continuo com esse ponto de vista. Penso que o ônus da prova está com quem achar que definir a noção de estímulo sensorial necessariamente depende da introdução do conceito de comportamento na acepção relevante.

Em segundo lugar, a meu ver, os seres vivos em geral comportam-se e a própria noção de viver tem relação íntima com a de comportar-se (cf. Lazzeri 2015a). Caso eventualmente haja seres vivos que não possuam receptores que lhes permitam ser suscetíveis a estimulações sensoriais - como alega Tonneau em (II) -, então uma das condições que compõem o definiens tanto de (D.1) como de (D.2), a saber, aquela em que figura a noção de estímulo sensorial, tem de ser modificada. Em Lazzeri (2013a), eu trabalhei com a hipótese de que todos os seres vivos (mesmo, e.g., plantas e bactérias) são suscetíveis a uma ou mais formas de estimulações sensoriais.

Se tivermos de modificar a condição de (D.1) e (D.2) que contém a noção de estímulo sensorial, ela deverá ser substituída por uma condição que igualmente permita

5 . Carrara e Zilio (2013b), é claro, em uma de suas objeções anteriormente examinadas, podem também ter querido incluir o conceito de estímulo sensorial como um conceito quer requer explicação. excluir da extensão do definiendum muitas das atividades desenvolvimentais dos seres vivos (e.g., formação de órgãos, tecidos e patas). A meu ver, a referida condição - se é que teremos de fazer a modificação nela - poderia, se necessário, ser aprimorada por meio de disjunções, resultando na condição com a seguinte forma: a mudança do organismo que conta como comportamento é tal que sua etiologia envolve objetos, eventos ou condições do ambiente presente como estímulos sensoriais, ou ... (ou ainda ...). A(s) disjunção(ões) especificaria(m) estímulos análogos aos sensoriais, que participam, de maneira análoga aos sensoriais no caso de muitos dos seres vivos, como variáveis independentes no caso de alguns outros seres vivos (eventualmente até mesmo robôs). É claro, em tal caso, a condição de que a mudança do organismo que conta como comportamento é tal que sua etiologia envolve história de seleção na filogênese e/ou na ontogênese, no caso de (D.2), ou de que a mudança do organismo possua uma ou mais funções, no caso de (D.1), permaneceria inalterada. Assim, a modificação, caso se mostre requerida, é pequena.

\section{REFERÊNCIAS}

Austin, J. L. (1957). A plea for excuses. Proceedings of the Aristotelian Society, 57, 1-30.

Bennett, M. R., \& Hacker, P. M. (2003). Philosophical foundations of neuroscience. Oxford: Blackwell.

Botomé, S. P. (2013a). O conceito de comportamento operante como problema. Revista Brasileira de Análise do Comportamento, 9(1), 19-46.

Botomé, S. P. (2013b). O que significa "operar no ambiente"?. Revista Brasileira de Análise do Comportamento, 9(2), 79-98.

Carrara, K., \& Zilio, D. (2013a). O comportamento diante do paradigma behaviorista radical. Revista Brasileira de Análise do Comportamento, 9(1), 1-18.

Carrara, K., \& Zilio, D. (2013b). Abordagens ao conceito de comportamento: 1) o operante como problema; 2) a pele como fronteira; 3) um estudo sobre definições; 4) efeitos e consequências. Revista Brasileira de Análise do Comportamento, 9(2), 99-106.

Cook, R. T. (2009). A dictionary of philosophical logic. Edinburgh: Edinburgh University Press.

Copi, I. M. (1982). Introduction to logic (6 $6^{\text {th }}$ ed.). New York: Macmillan.

Gibson, J. J. (1960). The concept of the stimulus in psychology. American Psychologist, 15, 694-703.

Gilbert, M. (2010). Collective action. In T. O'Connor \& C. Sandis (Eds.), A companion to the philosophy of action (p. 67-73). Malden: Blackwell.

Harzem, P., \& Miles, T. R. (1978). Conceptual issues in operant psychology. New York: Wiley.

Laudan, L., Donovan, A., Laudan, R., Barker, P., Brown, H., Leplin, J., Thagard, P., \& Wykstra, S. (1986). Scientific change: Philosophical models and historical 
research. Synthese, 69, 141-223.

Lazzeri, F. (2013a). Um estudo sobre definições de comportamento. Revista Brasileira de Análise do Comportamento, 9(1), 47-65.

Lazzeri, F. (2013b). Sobre o conceito de comportamento: alguns breves comentários. Revista Brasileira de Análise do Comportamento, 9(2), 107-112.

Lazzeri, F. (2013c). Observações sobre o behaviorismo teleológico: Parte 2. Acta Comportamentalia, 21, 391408.

Lazzeri, F. (2014a). A conceptual difficulty with some definitions of behavior. Em J. Conte \& C. A. Mortari (Eds.), Temas em filosofia contemporânea (p.148-155). Florianópolis: NEL/UFSC.

Lazzeri, F. (2014b). On defining behavior: Some notes. Behavior and Philosophy, 41, 65-82.

Lazzeri, F. (2015a). Dynamic interactions with the environment make up our psychological phenomena: A review of Noë's Out of our heads. The Psychological Record, 65, 215-222.

Lazzeri, F. (2015b). On the place of behavior in the analysis of psychological categories. The Psychological Record, 65, 567-577.

Levitis, D. A., Lidicker Jr., W. Z., \& Freund, G. (2009). Behavioural biologists do not agree on what constitutes behaviour. Animal Behaviour, 78, 103-110.

Millikan, R. G. (1984). Language, thought, and other biological categories. Cambridge: MIT Press.

Millikan, R. G. (1989). In defense of proper functions. Philosophy of Science, 56, 288-302.

Millikan, R. G. (1993). What is behavior? A philosophical essay on ethology and individualism in psychology, part 1. In White queen psychology and other essays for Alice (p.135-150). Cambridge: MIT Press.

Moore, J. (2008). Conceptual foundations of radical behaviorism. Cornwall-on-Hudson: Sloan.

Pettit, P., \& Schweikard, D. (2006). Joint actions and group agents. Philosophy of the Social Sciences, 36, 18-39.

Skinner, B. F. (1976/1974). About behaviorism. New York: Vintage Books.

Skinner, B. F. (1981). Selection by consequences. Science, 213, 501-504.

Skinner, B. F. (1990). Can psychology be a science of mind? American Psychologist, 45, 1206-1210.

Sober, E. (1984). The nature of selection: Evolutionary theory in philosophical focus. Chicago: University of Chicago Press.

Todorov, J. C., \& Henriques, M. B. (2013). Porque o termo operante não é sinônimo de comportamento: comentários. Revista Brasileira de Análise do Comportamento, 9(2), 113-120.

Tonneau, F. (2013). Behavior and the skin. Revista Brasileira de Análise do Comportamento, 9(1), 66-73.

Tonneau, F. (2013b). Comentários Sobre o Comportamento. Revista Brasileira de Análise do Comportamento, 9(2), 121-123.
Wright, L. (1976). Teleological explanations: An etiological analysis of goals and functions. Berkeley: University of California Press. 